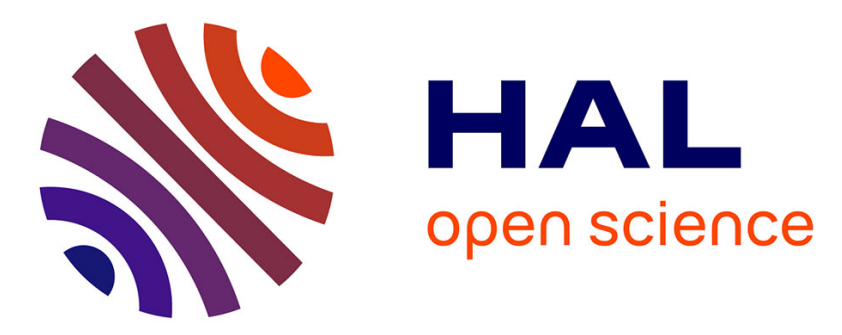

\title{
Acquisition of a bacterial RumA-type tRNA(uracil-54, C5)-methyltransferase by Archaea through an ancient horizontal gene transfer.
}

Jaunius Urbonavicius, Sylvie Auxilien, Hélène Walbott, Kalliopi Trachana, Beatrice Golinelli-Pimpaneau, Céline Brochier-Armanet, Henri Grosjean

\section{To cite this version:}

Jaunius Urbonavicius, Sylvie Auxilien, Hélène Walbott, Kalliopi Trachana, Beatrice GolinelliPimpaneau, et al.. Acquisition of a bacterial RumA-type tRNA(uracil-54, C5)-methyltransferase by Archaea through an ancient horizontal gene transfer.. Molecular Microbiology, 2008, 67 (2), pp.323-35. 10.1111/j.1365-2958.2007.06047.x . hal-02287548

\section{HAL Id: hal-02287548 https://hal.science/hal-02287548}

Submitted on 11 Nov 2020

HAL is a multi-disciplinary open access archive for the deposit and dissemination of scientific research documents, whether they are published or not. The documents may come from teaching and research institutions in France or abroad, or from public or private research centers.
L'archive ouverte pluridisciplinaire HAL, est destinée au dépôt et à la diffusion de documents scientifiques de niveau recherche, publiés ou non, émanant des établissements d'enseignement et de recherche français ou étrangers, des laboratoires publics ou privés. 


\section{Acquisition of a bacterial RumA-type tRNAluracil-54, C5)-methyltransferase by Archaea through an ancient horizontal gene transfer}

Jaunius Urbonavičius, ${ }^{1 \ddagger}$ Sylvie Auxilien, ${ }^{1 \ddagger}$

Hélène Walbott, ${ }^{1}$ Kalliopi Trachana, ${ }^{1}$

Béatrice Golinelli-Pimpaneau, ${ }^{1}$

Céline Brochier-Armanet ${ }^{2,{ }^{*}}$ and Henri Grosjean ${ }^{1,3 * \neq}$

${ }^{1}$ Laboratoire d'Enzymologie et Biochimie Structurales,

CNRS, 1 avenue de la Terrasse, 91190, Gif-sur-Yvette,

France.

${ }^{2}$ EA 3781 EGEE (Evolution Génome, Environnement),

Université de Provence, Aix-Marseille I, Marseille,

France.

${ }^{3}$ Univ Paris-Sud, IGM, UMR8621, F-91405 Orsay,

France.

\section{Summary}

The Pyrococcus abyssi genome displays two genes possibly coding for S-adenosyl-L-methioninedependent RNA(uracil, C5)-methyltransferases (PAB0719 and PAB0760). Their amino acid sequences are more closely related to Escherichia coli RumA catalysing the formation of 5-methyluridine $\left(\mathrm{m}^{5} \mathrm{U}\right)$ 1939 in 23S rRNA than to $E$. coli TrmA (tRNA methyltransferaseA) methylating uridine-54 in tRNA. Comparative genomic and phylogenetic analyses show that homologues of PAB0719 and PAB0760 occur only in a few Archaea, these genes having been acquired via a single horizontal gene transfer from a bacterial donor to the common ancestor of Thermococcales and Nanoarchaea. This transfer event was followed by a duplication event in Thermococcales leading to two closely related genes. None of the gene products of the two $P$. abyssi paralogues catalyses in vitro the formation of $\mathrm{m}^{5} \mathrm{U}$ in a $P$. abyssi rRNA fragment homologous to the bacterial RumA substrate. Instead, РАB0719 enzyme (renamed PabTrmU54) displays an identical specificity to $\operatorname{TrmA}$, as it catalyses the in vitro formation of $\mathrm{m}^{5} \mathrm{U}-54$ in tRNA. Thus, during

Accepted 24 October, 2007. *For correspondence. E-mail henri. grosjean@ igmors.u-psud.fr; Tel. (+33) 169154637; Fax (+33) 1 69154629. 'Present address: Laboratoire de Chimie Bacterienne, CNRS, Institut de Biologie Structurale et de Microbiologie, Marseille, France. ${ }^{\top}$ The first two and last two authors contributed equally to this work.

Journal compilation @ 2007 Blackwell Publishing Ltd No claim to original French government works evolution, at least one of the two $P$. abyssi RumA-type enzymes has changed of target specificity. This functional shift probably occurred in an ancestor of all Thermococcales. This study also provides new evidence in favour of a close relationship between Thermococcales and Nanoarchaea.

Introduction

Naturally occurring RNAs always contain a number of nucleosides that are post-transcriptionally modified by specific enzymes acting on their base and/or their 2'-hydroxyl group of the ribose backbone. To date, 107 structurally distinguishable modified nucleosides originating from different types of RNAs of diverse organisms have been reported; most of them (more than 90) were found in tRNAs [for a complete list of naturally occurring modified nucleosides and their conventional symbols, see http://library.med.utah.edu/RNAmods/ (Limbach et al., 1994; McCloskey and Crain, 1998)].

One frequently encountered modified nucleoside in RNA is 5-methyluridine $\left(\mathrm{m}^{5} \mathrm{U}\right.$, also designated $\mathrm{rT}$ for ribothymidine). In transfer RNAs of most organisms examined so far, $\mathrm{m}^{5} \mathrm{U}$ is invariably found at position $54\left(\mathrm{~m}^{5} \mathrm{U}-54\right)$, in the so-called T-loop (loop of tRNA usually harbouring ribothymidine) (see http://www.staff.uni-bayreuth.de/ btc914/ search/index.html; Edmonds et al., 1991; Kowalak et al., 1994; Sprinzl and Vassilenko, 2005). The enzyme catalysing the formation of $\mathrm{m}^{5} \mathrm{U}-54$ in tRNA was first discovered in Escherichia coli (Fleissner and Borek, 1962; Svensson et al., 1963; Greenberg and Dudock, 1980) and initially named RUMT for RNA Uridine MethylTransferase but is now renamed TrmA for tRNA methyltransferase A. This enzyme (EC.2.1.1.35) uses S-adenosyl-L-methionine (S-AdoMet) as methyl donor. The corresponding E. coli $\operatorname{trmA}$ gene was identified years later, cloned and sequenced (Ny and Bjork, 1980; Gustafsson et al., 1991). Search in fully sequenced bacterial genomes reveals that $\operatorname{trmA}$ orthologues are present in many but not all bacteria analysed to date (essentially in Beta-, Epsilon- and Gammaproteobacteria, see below). Indeed, in Alpha- and Deltaproteobacteria, Cyanobacteria and Deinococci, one finds instead a trmFO gene coding for an evolutionary 
unrelated tRNA(uracil-54, C5)-methyltransferase, using tetrahydrofolate instead of S-AdoMet as the methyl donor (Urbonavicius et al., 2005; 2007).

A eukaryotic homologue of $\operatorname{trmA}$, called TRM2, was identified in the genome of Saccharomyces cerevisiae (Nordlund et al., 2000). Its gene product Trm2p is responsible for the same S-AdoMet-dependent formation of $\mathrm{m}^{5} \mathrm{U}-54$ in both cytoplasmic and mitochondrial tRNAs (Hopper et al., 1982). Sequence analysis shows that the genes coding for the yeast Trm2p and the bacterial TrmA proteins belong to the same cluster of orthologous groups (COG2265, http://www.ncbi.nlm.nih.gov/COG/ new; Tatusov et al., 2001; 2003). They are found in almost all sequenced eukaryotic genomes. It has been suggested that the ancestor of the TRM2/trmA genes emerged early in bacterial evolution and was subsequently transferred to eukaryotes through mitochondrial endosymbiosis (Anantharaman et al., 2002).

In the genome of E. coli, two additional homologous genes (rumA and rumB) are found beside the trmA. They encode two distinct site-specific S-AdoMet-dependent rRNA(uracil, C5)-methyltransferases, RumA and RumB, targeting uridine at positions 1939 and 747 of the E. coli 235 rRNA respectively (Agarwalla et al., 2002; Madsen et al., 2003). RumA homologues are found in the genomes of various bacteria and RumB homologues seem restricted to Gammaproteobacteria (see below). Both RumA and RumB belong to the same cluster of orthologous groups as TrmA and Trm2p (COG2265), suggesting that this large family of S-AdoMet-dependent RNA(uracil, C5)-methyltransferases probably emerged from a single common ancestor (Anantharaman et al., 2002). Moreover, the presence of up to three paralogues in some bacterial genomes (as E. coli) suggests that duplication events occurred during the evolution of the bacterial domain, some of them being probably followed by changes of target specificity.

The modified nucleoside $\mathrm{m}^{5} \mathrm{U}$ has never been detected in bulk tRNA from Archaea analysed to date, except for the closely related members of the Thermococcales order (i.e. Thermococcus and Pyrococcus genera). In these hyperthermophilic organisms, $\mathrm{m}^{5} \mathrm{U}$ is partially or totally hypermodified into a thiolated derivative (2-thio-5methyluridine, $s^{2} m^{5} \mathrm{U}$ ), depending on the temperature at which the cells are grown (Edmonds et al., 1991; Kowalak et al., 1994). In agreement with this observation, a genomic survey of the completely sequenced archaeal genomes reveals that only members of the Thermococcales and Nanoarchaea orders contain homologues of the trmA/TRM2/rumA/rumB family (Urbonavicius et al., 2007). Interestingly, all members of the Thermococcales lineage contain two homologous genes while a single homologue is present in the genome of Nanoarchaeum equitans, the only representative of the Nanoarchaea lineage. The amino acid sequences of these archaeal enzymes are more similar to E. coli RumA than to E. coli TrmA or $S$. cerevisiae Trm2p suggesting they might be involved in rRNA rather than TRNA modification. However, as the activity of an S-AdoMet-dependent tRNA(uracil-54, C5)methyltransferase was clearly demonstrated in vitro in cell extract of Pyrococcus furiosus (Constantinesco et al., 1999), we wanted to determine whether one of the two potential open reading frames (ORFs) detected in the Thermococcales genomes may code for a site-specific tRNA(uracil-54, C5)-methyltransferase. Indeed, the possibility exists that an enzyme phylogenetically unrelated to TrmA-like enzyme may catalyse the C5-methylation of uracil-54 in tRNAs from Archaea.

To shed light on this problem, the genes from Pyrococcus abyssi (PAB0719 and PAB0760) were cloned, and the enzymatic activity of each of the two purified recombinant proteins was tested in vitro with transcripts of tRNAs and rRNA fragment as potential substrates. Here, we show that only one of the two candidates, PAB0719 protein, catalyses the S-AdoMet-dependent site-specific formation of $\mathrm{m}^{5} \mathrm{U}-54$ in tRNA and none of the candidates can methylate an rRNA fragment homologous to a substrate of E. coli RumA. Detailed phylogenetic analyses reveal that this S-AdoMetdependent tRNA(uracil-54, C5)-methyltransferase was acquired by the common ancestor of Thermococcales and Nanoarchaea through a single horizontal gene transfer (HGT) of a rumA-type gene from a bacterial donor. This strongly suggests that a functional shift occurred in the archaeal lineage.

\section{Results}

Putative genes coding for RNA(uracil, C5)-methyltransferases in archaeal genomes

A genomic survey of 410 complete genome sequences available at $\mathrm{NCBI}$ enabled us to retrieve 456 homologues of RNA(uracil, C5)-methyltransferases (31 RumB-type, 303 RumA-type, 49 Trm2-type, 64 TrmA-type and 9 archaeal sequences). In Archaea, two homologues were detected only in members of the Thermococcales group (P. abyssi, P. furiosus, Pyrococcus horikoshii and Thermococcus kodakarensis), while only one homologue is found in the genome of $N$. equitans, the single representative of the recently proposed new archaeal phylum Nanoarchaea (Huber et al., 2002).

Figure 1 schematically shows the conserved motifs/ domains identified in the COG2265 family of RNA(uracil, C5)-methyltransferases (parts 1-9), including the proteins from P. abyssi and N. equitans (part 9, for detailed sequence alignment, see Fig. S1). Sequence alignment of all the RumA, RumB, TrmA, Trm2p homologues 


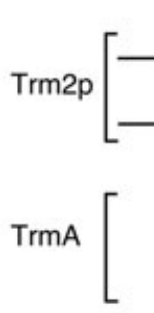

TRAM
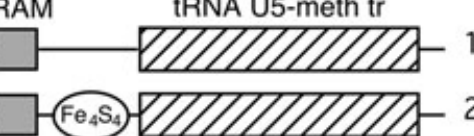

RumB

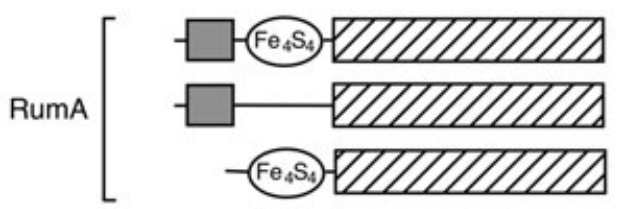

PAB0719, PAB0760 other Thermococcales and $N$. equitans

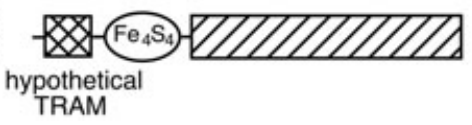

Fig. 1. Schematic view of the organization of conserved regions of the sequences of the S-AdoMet-dependent RNA(uracil, C5)-methyltransferases family. The signature sequence for the catalytic core domain of the RNA(uracil, C5)-methyltransferases family (annotated as 'tRNA U5-meth tr' in the sequence database) encompassing S-AdoMet-binding motifs and adopting the Rossmann-like fold is indicated by dashed boxes, the detailed sequence information being provided in Fig. S1. In some sequences a conserved 10- to 12-amino-acid-long motif is found at the $\mathrm{N}$-terminal part. Together with a fourth cysteine, a cysteine triad of this motif probably forms a characteristic iron-sulphur cluster [4Fe-4S] (illustrated by a $\mathrm{Fe}_{4} \mathrm{~S}_{4}$ encircled symbol), as demonstrated in the crystal structure of RumA (Lee et al., 2004). The sequence of this motif is usually CXX(FYA) XXCGGC (parts 2, 4, 6, 8 and 9; for details see Figs S2 and S3), except for the RumB homologues for which a slightly different motif exists (CXX(FY)XXXXC(RTH)SC) (part 5 , encircled grey symbol). In the other sequences, the motif is absent or degenerated in such a way that it may no longer form an iron-sulphur cluster (parts 1, 3 and 7). Finally, the presence of a 50- to 80-amino-acid-long TRAM motif as defined by Anantharaman et al. (2001) for the yeast Trm2p and E. coli MiaB domain is symbolized by a grey rectangle. The presence of a 'hypothetical TRAM' in archaeal enzymes is indicated by an open dashed rectangle (for definition of the 'hypothetical TRAM', see text). Parts 1 through 9 correspond to the following enzymes. Part 1 corresponds to the domain organization of the experimentally verified Trm2p of $S$. cerevisiae (569 amino acids) and homologues of most eukaryotes; part 2 to Trm2p homologues of all fungi (except S. cerevisiae and its close relative Candida glabrata), Entomoeba and land plants; part 3 to the experimentally verified TrmA of E. coli (366 amino acids) as well as homologues of Betaand Gammaproteobacteria and a few Epsilonproteobacteria; part 4 to homologues of all other Epsilonproteobacteria; part 5 to all RumB-type enzymes (present only in Gammaproteobacteria, including the genuine E. coli RumB with 375 amino acids); part 6 to the majority of RumA-type homologues (including E. coli with 433 amino acids); part 7 to RumA homologues found in some bacteria such as Deinococci, certain Firmicutes and certain Actinobacteria; part 8 to RumA homologues of Chlamydia and certain Spirochetes; part 9 to all RumA-like proteins present in the archaeal

Thermococcales (including PAB0719, 405 amino acids, and PAB0760, 410 amino acids) and in N. equitans (NEQ053, 447 amino acids). shows a conserved C-terminal part annotated as tRNA(uracil, C5)-methyltransferase domain in the Pfam database (PF05958.1 - about $340 \pm 30$ amino acids, shaded boxes in Fig. 1). This corresponds to the conserved catalytic core domain encompassing the catalytic residues responsible for the RNA(uracil, C5)methyltransferase activity and the six characteristic motifs (X, I, II, IV, VI and VIII) responsible for the binding of S-AdoMet (reviewed in Fauman et al., 1999; Martin and McMillan, 2002; Schubert et al., 2003; Bujnicki et al., 2004). From the crystal structure of E. coli RumA, this conserved domain was demonstrated to adopt the typical class I S-AdoMet-dependent methyltransferase fold (also designated Rossmann-like fold; Lee et al., 2004).

In contrast, the $\mathrm{N}$-terminal part of the sequences is more variable. In most sequences, a 10- to 12-amino-acid sequence encompassing a cysteine triad is found (Fig. 1, parts 2, 4-6, 8 and 9). With a fourth cysteine, this motif may form a characteristic iron-sulphur cluster [4Fe-4S], as demonstrated in E. coli RumA (Agarwalla et al., 2004; Lee et al., 2004). Interestingly, in several sequences this motif is absent or degenerated in such a way that it may no longer form an iron-sulphur cluster (Fig. 1, parts 1, 3 and $7)$. This suggests that such iron-sulphur cluster was present in the ancestral protein, and has been lost along the evolution of the Trm2p/TrmA/RumA. Therefore, it may not be essential for the catalytic formation of ribothymidine in certain RNAs.

In addition to the iron-sulphur cluster, all the eukaryotic Trm2 $p$ and most bacterial RumA homologues contain a conserved motif of 50-80 amino acids called TRAM domain (grey box in Fig. 1) in the Pfam database (PF01938.10; Anantharaman et al., 2001; Lee et al., 2004). Although no TRAM domain is detected in the archaeal sequences, their $\mathrm{N}$-terminal sequence displays some similarity with the genuine TRAM domain. In fact, the $\mathrm{N}$-terminal part of the archaeal sequences is only four amino acids shorter than that of $E$. coli RumA (Fig. 1, part 6). Moreover this deletion seems to be located in a variable segment of TRAM as $S$. cerevisiae Trm2p has an insertion of seven amino acids in the same segment (see alignment of Fig. S1). This strongly suggests that the archaeal sequences nevertheless contain a TRAM-like domain (indicated as 'hypothetical TRAM' in Fig. 1, part 9).

In summary, comparison of the members of the S-AdoMet-dependent RNA(uracil, C5)-methyltransferase family revealed no apparent link between their target specificity and their domain organization. Consequently, one cannot unambiguously guess which one of the two archaeal sequences PAB0719 or PAB0760 may correspond to the tRNA(uracil-54, C5)-methyltransferase, whose activity was detected in $P$. furiosus cell extracts (Constantinesco et al., 1999). 


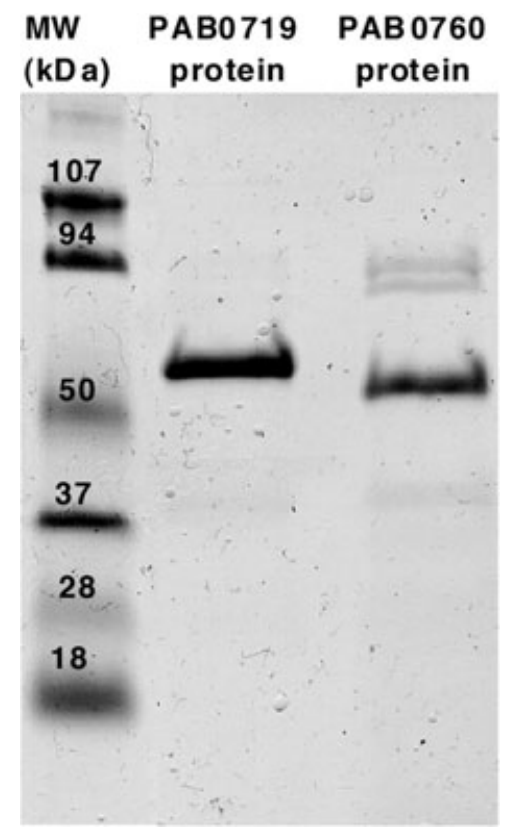

Fig. 2. Electrophoretic analysis of the purified recombinant PAB0719 and PAB0760 proteins. An SDS-PAGE was performed using $10 \%$ acrylamide gels, and the proteins were stained by Coomassie blue. Lane 1, molecular weight markers in $\mathrm{kDa}$; lane 2, PAB0719 protein (49 kDa); lane 3, PAB0760 protein (48.6 kDa). Both proteins were purified by Ni-affinity chromatography.

\section{Recombinant PAB0719 protein catalyses methylation at C5 of uridine in tRNA}

The recombinant PAB0719 and PAB0760 proteins, both tagged with six histidine residues at the $\mathrm{N}$-terminus, were successfully expressed in E. coli BL21 (DE3) CodonPlus $^{\mathrm{TM}}$ and purified to near homogeneity by affinity chromatography (Fig. 2). The enzymatic activity of both purified enzymes was tested at $50^{\circ} \mathrm{C}$, using [methyl- $\left.{ }^{3} \mathrm{H}\right]-$ AdoMet as methyl group donor and yeast tRNA ${ }^{\text {Asp }}$ transcript as substrate. The methyl group transfer activity was clearly shown with the recombinant PAB0719 enzyme, while under identical experimental conditions the PAB0760 protein did not show any significant incorporation of the radioactive methyl group into tRNA (Fig. 3).

Confirmation that only recombinant PAB0719 and not PAB0760 catalyses the formation of ribothymidine in tRNA and verification that the product of methyl transfer is $m^{5} U$ were obtained using synthetic $\left[\alpha^{32} P\right]-U T P$-labelled tRNA transcripts corresponding to the nucleotide sequence of a naturally occurring tRNA of $P$. abyssi. One of the two substrates used is the full-length tRNA ${ }^{\text {Asp }}$ (Fig. 4A), and the other one is its D-arm-truncated version, thus lacking the characteristic three-dimensional (3D)-fold generated by the T-loop/D-loop (loop of tRNA usually harbouring dihydrouridine) interactions (Fig. 4B).

$\left[\alpha^{32} P\right]-U T P$-labelled PabtRNA ${ }^{\text {Asp }}$ lacking the D-arm was incubated with either of the two enzymes in the presence of S-AdoMet, and then hydrolysed into $5^{\prime}-\left[{ }^{32} \mathrm{P}\right]-$ nucleosides by nuclease P1. The resulting RNA digests were then separated by two-dimensional thin-layer chromatography (2D-TLC). The results indicate that no significant methylation occurs using the recombinant PAB0760 enzyme (compare Fig. 4E with Fig. 4C), while the formation of $\mathrm{m}^{5} \mathrm{U}$ is clearly visible with the PAB0719 enzyme (Fig. 4D). The activity of the PAB0719 enzyme was then examined as a function of time for the two different tRNA substrates and at two different temperatures $\left(50^{\circ} \mathrm{C}\right.$ and $80^{\circ} \mathrm{C}$; Fig. $4 \mathrm{~F}$ and $\mathrm{G}$ ). At $50^{\circ} \mathrm{C}$, the tRNA lacking the D-loop is a better substrate than full-length tRNAAsp (Fig. 4F), whereas, at $80^{\circ} \mathrm{C}$, the full-length tRNA becomes the better substrate (Fig. 4G). This result can probably be explained by the unfolding of the truncated tRNA substrate at $80^{\circ} \mathrm{C}$ due to lack of self-stabilization through the D-loop/T-loop interaction that occurs in the full-length molecule (Grosjean and Oshima, 2007). At $50^{\circ} \mathrm{C}$, uracil-54 in the truncated substrate is more accessible to the enzyme than in the compact entire molecule, which probably explains why the methylation reaction occurs more easily in the D-loop-truncated substrate. The same observation has been made for 1-methyladenosine and pseudouridine formation in tRNAs at positions $57 / 58$ and 55 respectively (Grosjean et al., 1996; Becker et al., 1997; Gu et al., 1998; Constantinesco et al., 1999; Hur et al., 2006).

Same experiments at $50^{\circ} \mathrm{C}$ and $80^{\circ} \mathrm{C}$ were performed with the recombinant enzymes PAB0719 and PAB0760 but tested with $\left[\alpha{ }^{-32} \mathrm{P}\right]$-UTP-labelled fragment of $P$. abyssi 235 rRNA (56 nucleotides in length; Fig. 5). This putative substrate sequence is homologous to a fragment (56 nucleotides) of $E$. coli $23 S$ rRNA used previously to test the ability of $E$. coli RumA to site-specifically methylate C5

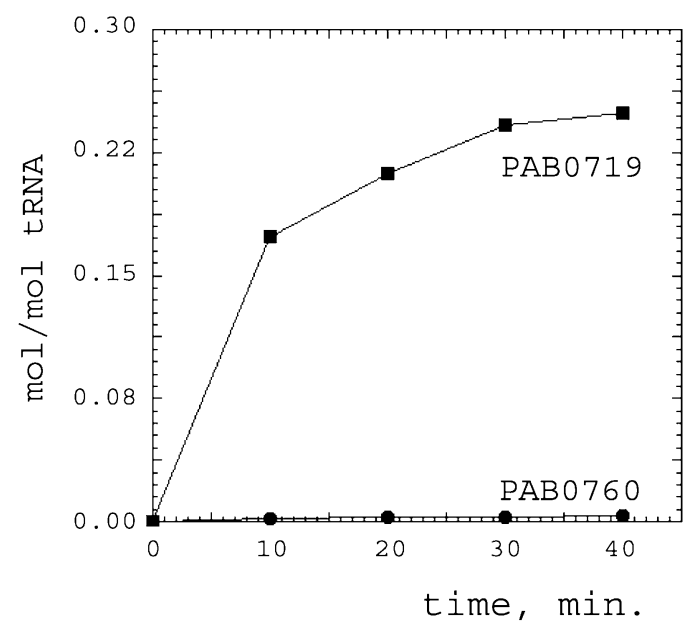

Fig. 3. tRNA methyltransferase activity of the PAB0719 and PAB0760 proteins. Kinetics at $50^{\circ} \mathrm{C}$ of incorporation of $\left[{ }^{3} \mathrm{H}\right]$-methyl group from radiolabelled S-AdoMet into yeast tRNA ${ }^{\text {Asp }}$ by PAB0719 (filled squares) and PAB0760 (filled circles) enzymes (for details see Experimental procedures). 


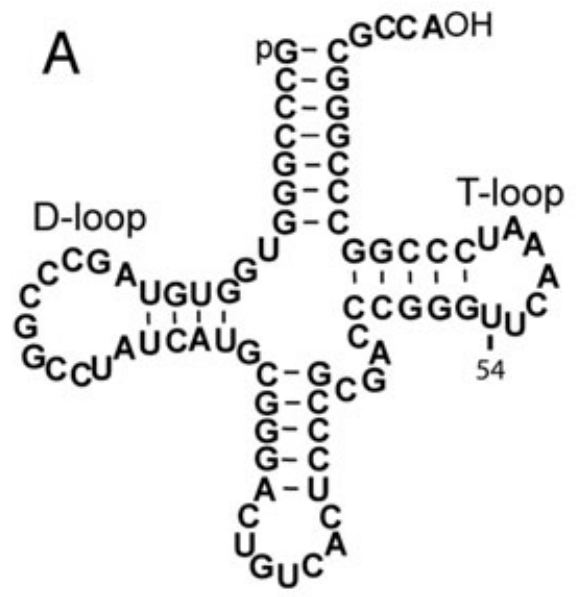

Pab-tRNA-Asp
B

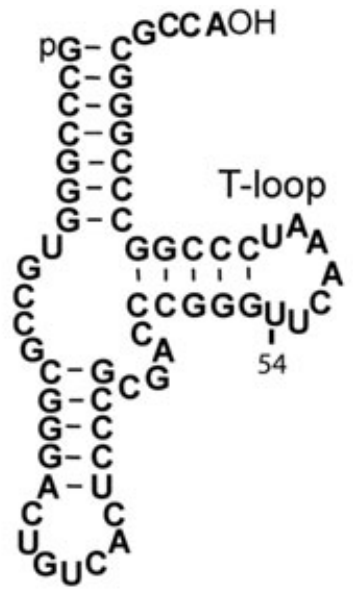

Pab-tRNA-Asp $\Delta$ D
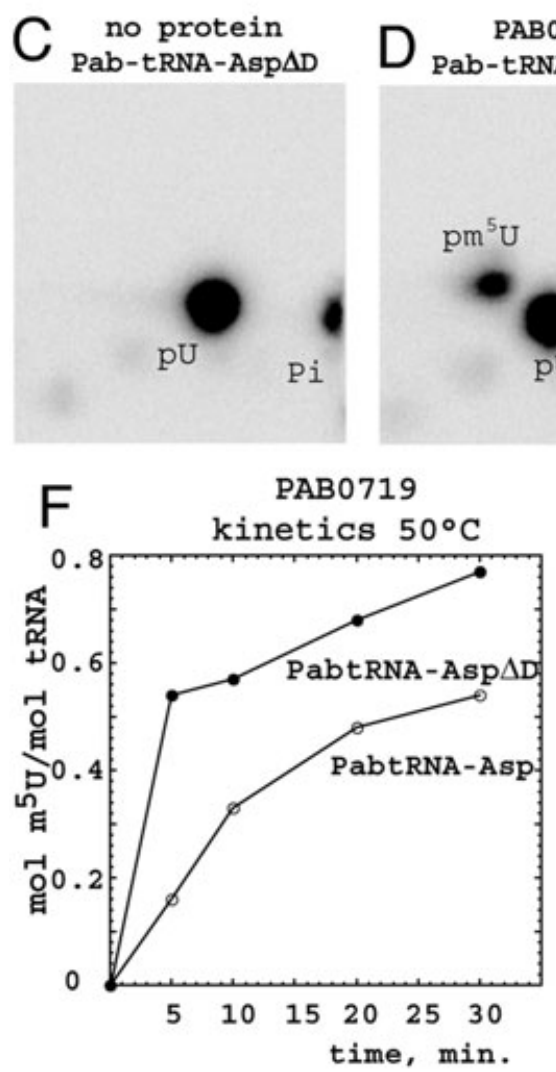
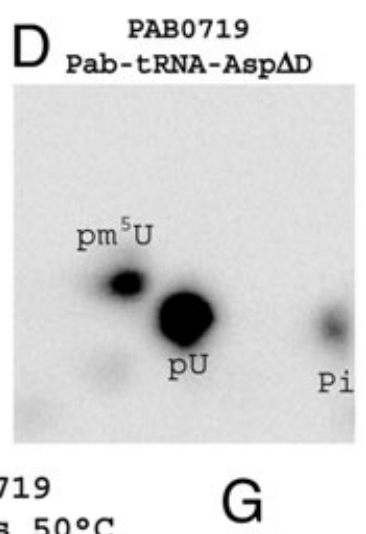

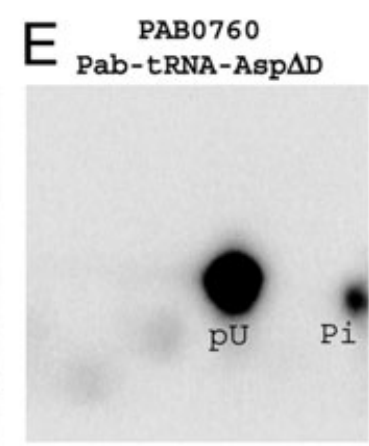

PAB0719

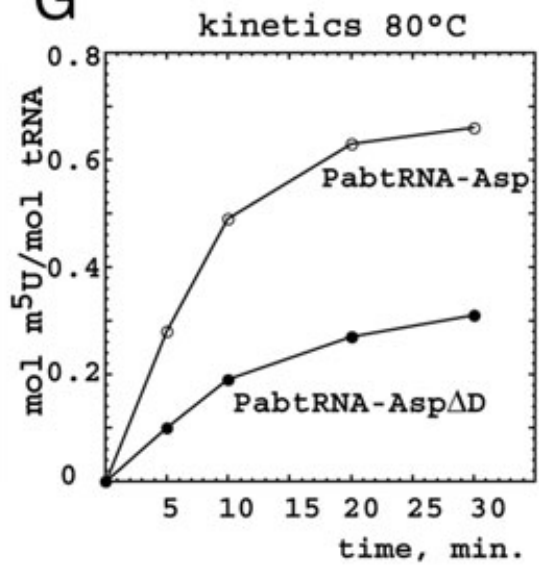

Fig. 4. Enzymatic activity of the PAB0719 and PAB0760 proteins on P. abyssi tRNA ${ }^{\text {Asp }}$. A. Sequence of the pabtRNA ${ }^{\text {Asp }}$ substrate. B. Sequence of the PabtRNA ${ }^{\text {Asp }}$, lacking the D-arm (Pab-tRNA- $\Delta$ D).

C-E. Autoradiograms of the TLC plates (2D-TLC) corresponding to the Pab-tRNA- $\Delta \mathrm{D}$ incubated for $30 \mathrm{~min}$ at $50^{\circ} \mathrm{C}$ without protein (C), with PAB0719 protein (D) or PAB0760 protein $(E)$ and digested with nuclease $\mathrm{P} 1$. F. Time-course of $\mathrm{m}^{5} \mathrm{U}-54$ formation at $50^{\circ} \mathrm{C}$ catalysed by the PAB0719 protein. The enzyme was incubated in the presence of S-AdoMet and $\left[\alpha{ }^{-32} \mathrm{P}\right]-$ UTP-labelled pabtRNA ${ }^{\text {Asp }}$ (open circles) or PabtRNA ${ }^{\text {Asp }}$ lacking the D-arm (filled circles).

G. Same as in $(F)$ but time-course of $m^{5} \mathrm{U}-54$ formation was performed at $80^{\circ} \mathrm{C}$ (more details are in Experimental procedures). of uridine at position 1939 (indicated by an arrow in Fig. 5; Madsen et al., 2003). Results from 2D-TLC analysis of the nuclease $\mathrm{P} 1$ digestion products indicate that none of these two enzymes can methylate any uridine in this rRNA fragment (data not shown). These results favour the idea that PAB0719 enzyme is specific for tRNA and has no dual specificity. Concerning PAB0760 protein, preliminary results using other rRNA fragments indicate that the enzyme is active but the exact uridine target remains to be identified (S. Auxilien et al., in preparation).
The methylated uridine product of PAB0719 is $\mathrm{m}^{5} \mathrm{U}$ at position 54 in $t R N A$

The position of the methylation in tRNA catalysed by PAB0719 enzyme was easily identified. Indeed, in pabtR$N A^{\text {Asp }}$, a tandem of $U$ exists only at positions 54 and 55 (Fig. 4A and B). Therefore, complete digestion of $\left[\alpha^{32} \mathrm{P}\right]-$ UTP-labelled tRNA with RNase T2 generates $3^{\prime}-\left[{ }^{32} \mathrm{P}\right]-$ nucleosides with all the $\left[{ }^{32} \mathrm{P}\right]-U M P$ originating exclusively from position 54 (nearest neighbour analysis). Figure 6 


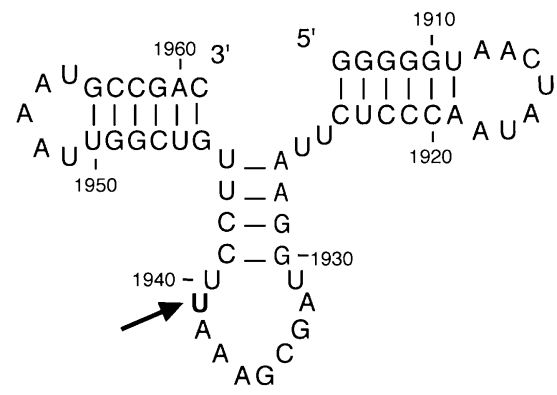

Fig. 5. Pyrococcus abyssi $23 \mathrm{~S}$ ribosomal RNA fragment tested as potential substrate for the PAB0719 and PAB0760 enzymes. This rRNA fragment corresponding to domain IV sequence 1906-1961 (56-mer) of 23S ribosomal RNA is homologous to the substrate of E. coli RumA that has previously been used in vitro (Madsen et al., 2003).

shows the autoradiograms of 2D-thin-layer plates resulting from the chromatographic analysis of the T2-nucleotide hydrolysates of D-loop-lacking tRNA ${ }^{\text {Asp }}$ preincubated at $50^{\circ} \mathrm{C}$ for $30 \mathrm{~min}$ in the absence of enzyme (Fig. 6A, control experiment) or with the recombinant PAB0719 protein (Fig. 6B). The presence of radiolabelled $3^{\prime}-\left[{ }^{32} \mathrm{P}\right]-\mathrm{m}^{5} \mathrm{U}$ is demonstrated only upon incubation with the PAB0719 enzyme (Fig. 6B), the fraction of nonmethylated uridine remaining in the RNase T2 hydrolysates (indicated as Up in Fig. 6B) being less than 10\%. Based on these evidences, we renamed the PAB0719 protein into the acronym name PabTrmU54.

\section{Enzymatic formation of $m^{5} \mathrm{U}-54$ in tRNA is dependent on the presence of $\mathrm{Mg}^{2+}$}

During the initial optimization of the experimental conditions to test the PAB0719 activity, we noticed that the yield of $\mathrm{m}^{5} \mathrm{U}-54$ absolutely depends on the presence of $\mathrm{Mg}^{2+}$, with an optimal concentration of about $5 \mathrm{mM}$. To better illustrate the effect of $\mathrm{Mg}^{2+}$, full-length or D-arm-lacking $P$. abyssitRNA ${ }^{\mathrm{Asp}}$ was incubated at $50^{\circ} \mathrm{C}$ in the absence of $\mathrm{Mg}^{2+}$ and in the presence of $0.5 \mathrm{mM}$ of chelating agent
EDTA. After $30 \mathrm{~min}$, the magnesium concentration was adjusted to $5 \mathrm{mM}$ and the enzymatic activity was followed for additional $45 \mathrm{~min}$. Figure 7 demonstrates that $\mathrm{m}^{5} \mathrm{U}-54$ can be formed only in the presence of $\mathrm{Mg}^{2+}$.

\section{The purified recombinant PAB0719 protein contains an iron-sulphur cluster}

The freshly purified PAB0719 protein is yellowish and its spectrum shows a peak at $405 \mathrm{~nm}$ (Fig. 8, continuous line). The yellow colour and the spectrum is typical for [4Fe-4S] cluster-containing proteins such as purified recombinant E. coli RumA (Agarwalla et al., 2004). Both properties disappear progressively upon storage of the protein for only a few hours at room temperature (Fig. 8, dotted line), showing oxidation of the [4Fe-4S] cluster of the protein.

\section{TrmU54 gene emerged in Archaea after a single HGT from Bacteria}

Maximum likelihood (ML) phylogenetic analyses of the 456 homologues composing the S-AdoMet RNA(uracil, C5)-methyltransferases family were performed with different evolutionary models which led to very similar trees. According to these phylogenies, a sample of 126 sequences (6 RumB-type, 76 RumA-type, 16 Trm2p-type, 19 TrmA-type and the 9 archaeal sequences) representative of the entire diversity of the S-AdoMet RNA(uracil, C5)-methyltransferases family was chosen for further phylogenetic analyses (Fig. 9 and Fig. S3). Bayesian and ML analyses (see Experimental procedures) provided very similar phylogenetic topologies (not shown). However, because of the restricted number of unambiguously aligned positions available for phylogenetic analyses (altogether 152), these phylogenies are globally poorly resolved [weak posterior probabilities (PP); and bootstrap values (BV), Fig. 9 and not shown]. Nevertheless, it is interesting to point out some peculiar well-supported groups of sequences (high PP and high BV).
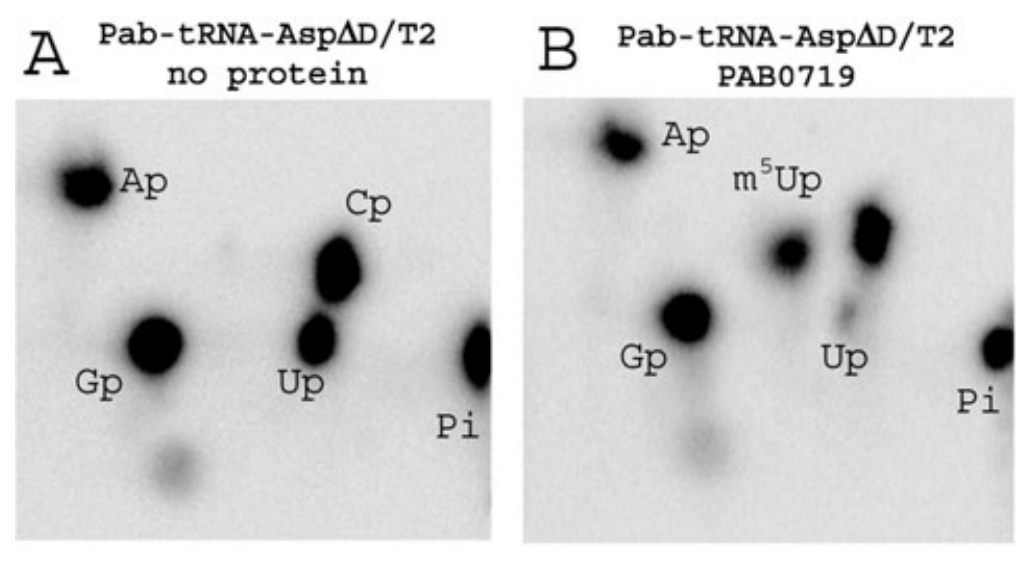

Fig. 6. Formation of $\mathrm{m}^{5} \mathrm{U}-54$ catalysed by the PAB0719 protein. 2D-TLC of RNase T2 digest of pabtRNA ${ }^{\mathrm{Asp}} \triangle \mathrm{D}$ incubated for $30 \mathrm{~min}$ at $50^{\circ} \mathrm{C}$ without protein (control; $\mathrm{A}$ ) or with PAB0719 protein (B). Experimental procedures are detailed in Grosjean et al. (2007). 


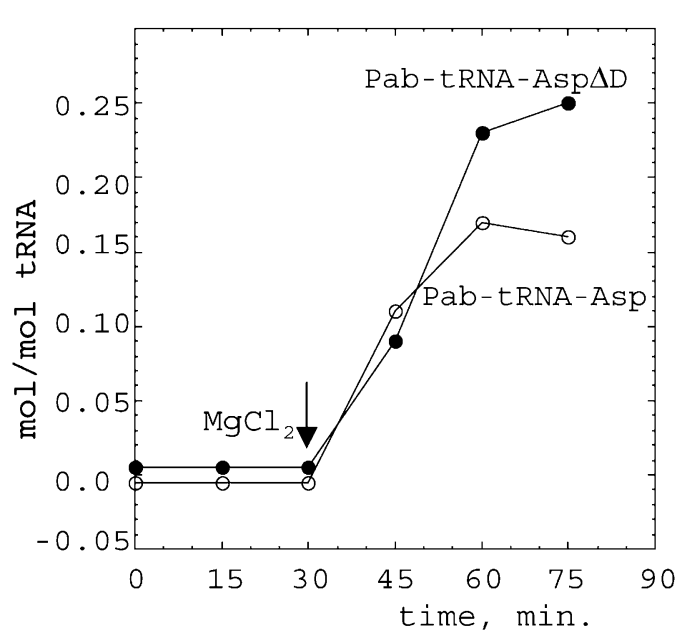

Fig. 7. Influence of $\mathrm{Mg}^{2+}$ on enzymatic formation of $\mathrm{m}^{5} \mathrm{U}-54$. PAB0719 protein was incubated with PabtRNA $^{\text {Asp }}$ or ${ }_{\text {Pab }}$ tRNA ${ }^{\text {Asp }} \triangle D$ at $50^{\circ} \mathrm{C}$ in the standard reaction mixture, but containing $0.5 \mathrm{mM}$ EDTA instead of $5 \mathrm{mM} \mathrm{MgCl}_{2}$. For each tRNA, samples were withdrawn after 15 and $30 \mathrm{~min}$ of incubation, and $\mathrm{MgCl}_{2}$ was added to $5 \mathrm{mM}$ final concentration. Three more samples were withdrawn after an additional 15,30 and 45 min of incubation, and analysed by 2D thin-layer chromatography after digestion with nuclease P1.

A first well-defined group of proteins, referred to as TrmA cluster (see upper part of Fig. 9, with yellow background), includes all the TrmA-type sequences (PP $=1.0$ and BV $=91 \%$ ). These are found in some Epsilon-, Betaand Gammaproteobacteria, including that of E. coli. A second group of sequences, referred as RumB cluster (lower part of Fig. 1, with pink background, $\mathrm{PP}=0.92$ and $\mathrm{BV}=87 \%$ ), encompasses all the RumB-type sequences. These are present only in a few Gammaproteobacteria, mainly Enterobacteriales and Pasteurellales, including E. coli RumB. In contrast with these two monophyletic groups restricted to Proteobacteria (and mainly Gammaproteobacteria), the RumA-type sequences are widespread among Bacteria (Fig. 1, white background). These are present in almost all of bacterial phyla, such as Acidobacteria, Actinobacteria, Aquificales, Chlorobi/ Bacteroidetes, Planctomycetales/Verrucomicrobiales/ Chlamydia, Chloroflexi, Cyanobacteria, Deinococci/ Thermus, Firmicutes, Fusobacteria and Proteobacteria except in the Epsilonproteobacterial subgroup (Fig. 1; Figs S2 and S3). This strongly supports the possibility that the ancestor of all living Bacteria had a RumA-type sequence that was mainly vertically transmitted during bacterial evolution and that the TrmA-type and RumBtype sequences originated secondarily by gene duplication in the Proteobacterial lineage from RumA-type ancestors.

As far as the archaeal sequences are concerned, they are detected only in the Thermococcales lineage and in $N$. equitans. Interestingly, these sequences form a welldefined monophyletic group (Fig. 9, with dark grey back- ground; $\mathrm{PP}=1.0$ and $\mathrm{BV}=78 \%$ ) that clearly emerges from the RumA cluster. This strongly suggests that the ancestor of Thermococcales and $N$. equitans acquired a RumA-type sequence by a single HGT from a bacterial donor. Unfortunately, given the poor resolution of our phylogenetic tree, the bacterial donor cannot be identified with confidence. Moreover, our tree shows that a duplication event occurred in the Thermococcales lineage after its divergence from $N$. equitans, leading to two groups of paralogues $\mathrm{P} 1$ and $\mathrm{P} 2$ (see position of white circle at the node in Fig. 9). Group P1 contains the P. abyssi sequence (PAB0719) involved in the formation of $\mathrm{m}^{5} \mathrm{U}-54$ in tRNA (this work), and group P2 contains the PAB0760 sequence most probably involved in rRNA base modification (S. Auxilien et al., in preparation).

The case of the Trm2p family of enzymes is surprising. Indeed, because of the possible mitochondrial origin of the Trm2-type sequences (Anantharaman et al., 2002), together with the fact that contemporary $S$. cerevisiae Trm2p and E. coli TrmA enzymes have identical catalytic functions (they both catalyse the site-specific formation of $m^{5} U-54$ in tRNA), we expected that the Trm2p-type sequences would be closely related to the TrmA-type sequences and form a monophyletic group including sequences from Alphaproteobacteria. At variance with these expectations, our phylogenetic analyses show that: (i) genomes of Alphaproteobacteria do not contain TrmAtype sequences, (ii) Trm2p-type sequences are not closely related to the TrmA cluster, and (iii) Trm2p-type sequences do not form a monophyletic group but, on the contrary, are mixed with RumA-type sequences (Fig. 9, blue background). Thus, together with the fact that the domain organization of the Trm2p-type sequences is more similar to that of RumA-type enzymes than to the

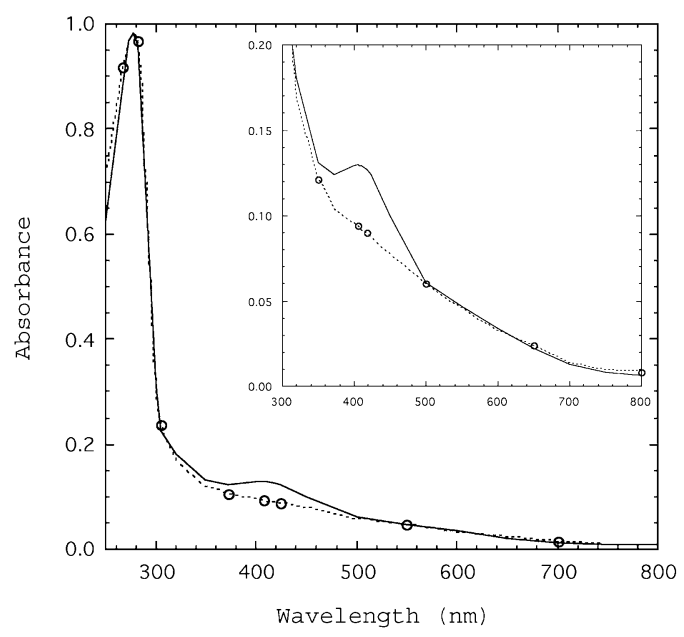

Fig. 8. UV-visible spectra of $20 \mu \mathrm{M}$ freshly purified $\mathrm{PAB} 0719$ protein (continuous line) or PAB0719 protein stored for 1 day at $18^{\circ} \mathrm{C}$ (dotted line). 


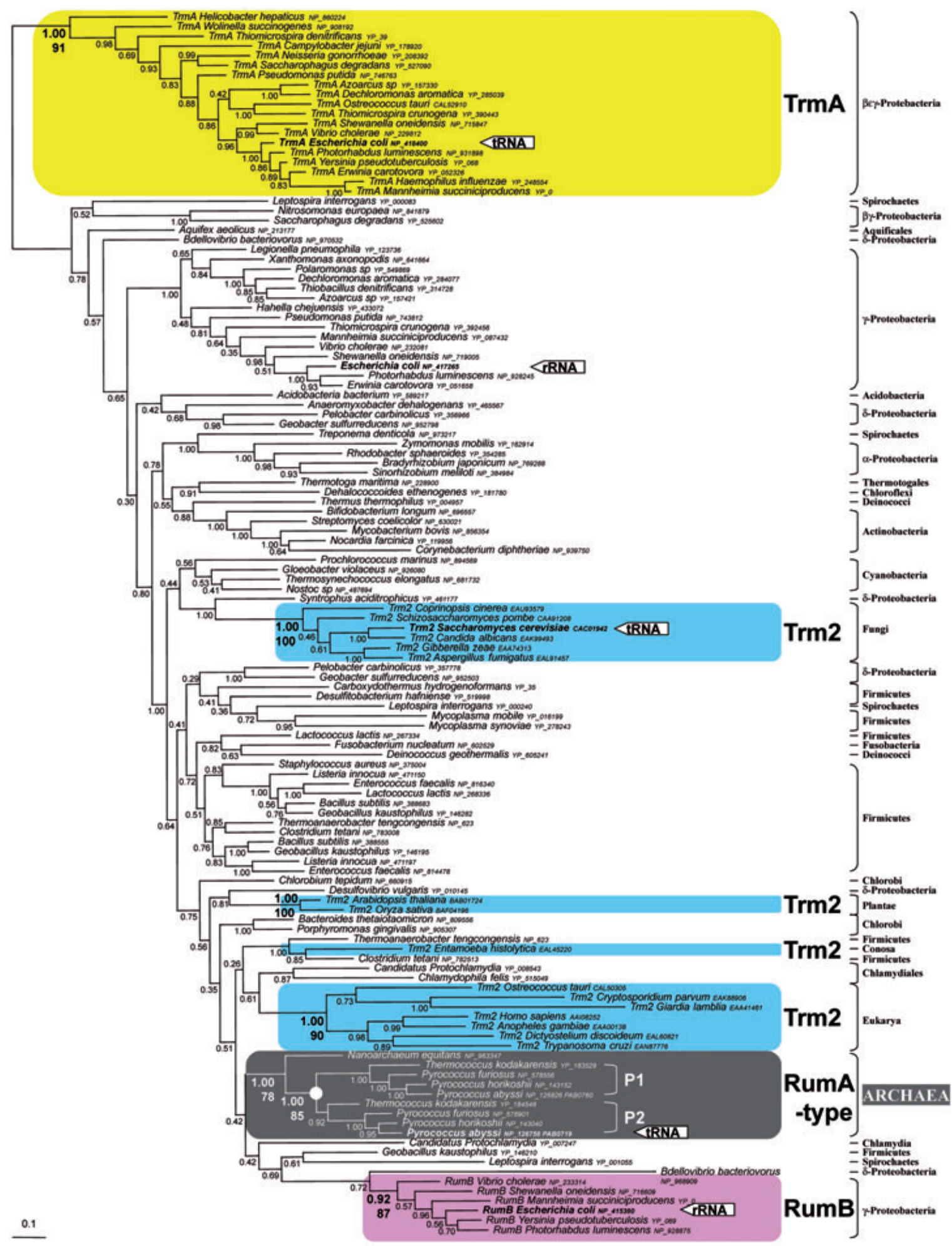

Fig. 9. Bayesian unrooted phylogenetic tree of 126 sequences representative of the diversity of the S-AdoMet-dependent RNA(uracil, C5)-methyltransferases. A total of 456 sequences were computed by MrBayes using mixed models and a $\Gamma$-correction to take into account the differences between evolutionary rates (see Experimental procedures). Numbers below or equal to 1.0 at nodes represent posterior probabilities (PP). For important clusters, bootstrap values (BV) are also provided. The scale bar represents the average number of substitutions per position. Enzymes with known functions are indicated by white arrows; all other enzymes should be considered as putative. The small white circle in the dark blue box indicates a duplication event. 
TrmA-type sequences (Fig. 1), we propose that the eukaryotic TRM2 genes derived from bacterial rumA-type sequences (and not from TrmA-type sequences) and were acquired through HGT.

\section{Discussion}

The PAB0719 (not PAB0760) protein is the genuine tRNA(uracil-54, C5)-methyltransferase in P. abyssi

In Archaea, $\mathrm{m}^{5} \mathrm{U}$ has been experimentally detected in bulk tRNAs isolated from only the hyperthermophiles P. furiosus and Thermococcus sp. (Edmonds et al., 1991; Kowalak et al., 1994). Contrary to the situation in E. coli, nothing is known about the presence of $\mathrm{m}^{5} \mathrm{U}$ in archaeal 23S rRNA. An enzymatic activity corresponding to a S-AdoMet-dependent tRNA(uracil-54, C5)methyltransferase was previously detected in crude extracts of $P$. furiosus (Constantinesco et al., 1999). Using sequences comparison coupled with in vitro enzymatic verification, the gene encoding the tRNA(uracil-54, C5)methyltransferase was identified in P. abyssi. In this genome, two homologous genes belong to the same cluster of orthologous groups (COG2265) including the genuine E. coli trmA and S. cerevisiae TRM2 (involved in $\mathrm{m}^{5} \mathrm{U}$ formation at position 54 in tRNA), as well as E. coli rum $A$ and rumB (involved in $\mathrm{m}^{5} \mathrm{U}$ formation at positions 1939 and 747 in 235 rRNA). Here we show that only the product of the PAB0719 gene (and not that of the PAB0760 gene) possesses the activity of a S-AdoMetdependent tRNA(uracil-54, C5)-methyltransferase in vitro. We suggest to rename this enzyme PabTrmU54.

This newly identified archaeal enzyme is site-specific for methylating $\mathrm{C} 5$ in uridine 54 of the T-loop and works on D-loop-truncated tRNA. As bacterial TrmA and eukaryotic Trm2p, PabTrmU54 is not dependent on the L-shaped 3D conformation of the tRNA molecule (Gu et al., 1996; Becker et al., 1997; 1998). Moreover, the activity of this archaeal enzyme is strictly dependent on the presence of magnesium ions. Similarly, the E. coli TrmA activity was shown to be stimulated in the presence of magnesium ions, but no clear-cut dependence was demonstrated (Ny and Bjork, 1980).

Also, like most fungal Trm2p proteins, TrmA of a few Epsilonproteobacteria, all RumB and a majority of RumA enzymes, the $P$. abyssi TrmU54 protein possesses a [4Fe-4S] cluster (see Fig. 1). Recent structural studies of non-oxidized E. coli RumA complexed with an RNA substrate showed that the [4Fe-4S] cluster is involved in RNA binding (Lee et al., 2005). The iron-sulphur cluster may also be important for the regulation of the enzyme activity under oxidative stress (Agarwalla et al., 2004), a property that could be important in the case of $P$. abyssi (possibly all Thermococcales) that normally grow under strictly anaerobic conditions with an optimal temperature of $100^{\circ} \mathrm{C}$.
tRNA(uracil-54, C5)-methyltransferase in

Thermococcales and Nanoarchaea derived from a RumA-type coding gene acquired by a single HGT from a bacterial donor

The phylogenetic analyses of the 456 sequences (including nine sequences from Archaea) composing the RNA(uracil-54, C5)-methyltransferases family suggest that a common ancestor of the Thermococcales and $N$. equitans acquired a RumA-type coding gene from a non-identified bacterial donor by a single HGT event. This possible relationship between the archaeal sequences and the RumA-type sequences is strengthened by similar domain organization (Fig. 1) and high sequence similarity (Fig. S1). Taking into account that we show that PAB0719 catalyses the formation of $\mathrm{m}^{5} \mathrm{U}-54$ in tRNA, and that PAB0760, which does not work on tRNA, is probably a genuine rRNA(uracil, C5)-methyltransferase (S. Auxilien et al., in preparation), two scenarios can be proposed for the emergence of distinct RNA site-specific archaeal RumA-like methyltransferases (Fig. 10). First, if the transferred ancestral bacterial gene coded for an enzyme acting on tRNA rather than on rRNA, then a functional shift from a tRNA to an rRNA modification activity should have occurred in the P1 lineage (as indicated by the circled symbol ' $\mathrm{F}$ ' in Fig. 10A). In this case, the unique $N$. equitans enzyme, as well as the paralogues P2 of Thermococcales, has probably conserved the ancestral function (i.e. $\mathrm{m}^{5} \mathrm{U}-54$ formation in tRNA, Fig. 10A). On the contrary (alternative scenario), if the ancestral function of the transferred bacterial gene was the modification of rRNA (as the present-day E. coli RumA), then the functional shift from an rRNA to a tRNA modification activity should have occurred in the P2 lineage (as indicated by the square boxed symbol ' $F$ ' in Fig. 10B). In this case, there should be a good chance that the unique presentday RumA-like enzyme found in $N$. equitans as well as the paralogues P1 of Thermococcales has kept the same specificity for rRNA as the genuine original bacterial RumA. However, the possibility also exists that the ancestral RumA-type enzyme had originally a more relaxed specificity than the present-day E. coli RumA having for example a 'dual specificity' for both rRNA and tRNA. In this case, functional specializations for tRNA or rRNA might have occurred after the duplication event in the Thermococcales lineage. Finally to complete the evolutionary scenario, it remains to determine the function of the present-day RumA-like of $N$. equitans.

\section{Evolutionary implications of the presence of a bacterial-type RNA methyltransferase in N. equitans}

Based on phylogenies of the RNA of the small subunit of the ribosome (16S rRNA), it was initially proposed that 
A

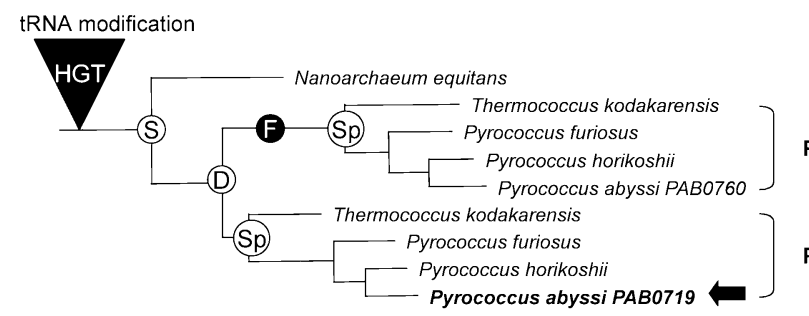

B

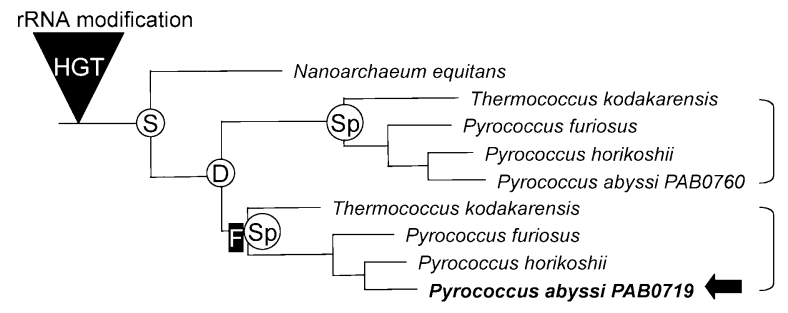

$N$. equitans was possibly the representative of a third archaeal phylum (Nanoarchaeota) that branches deeply in the archaeal phylogeny [i.e. before the split between the Euryarachaea and the Crenarchaea phyla (Huber et al., 2002; Waters et al., 2003)]. However, later phylogenetic and genomic analyses suggested that $N$. equitans is rather a fast evolving Euryarchaea possibly related to Thermococcales (Brochier et al., 2005; Makarova and Koonin, 2005). If $N$. equitans corresponds to a deeply branching archaeal phylum, as initially suggested by Huber et al. (2002), this implies that the RumA-like enzyme was acquired by an ancestor common to all living Archaea. To account for the absence of RumA-like enzymes in all archaeal lineages (except for Thermococcales and $N$. equitans), massive independent gene losses should have occurred in the archaeal domain. On the contrary, if $N$. equitans is related to Thermococcales only, this implies that a single HGT occurred in the ancestor of these two lineages, and no multiple gene losses need to be involved. The presence of genes coding for enzymes catalysing the formation of the $\mathrm{m}^{5} \mathrm{U}$ modification in the Thermococcales and $N$. equitans genomes is thus additional and strong evidence supporting the second possibility, i.e. the close relationship between the two lineages Thermococcales and Nanoarchaeota.

\section{Conclusion}

In conclusion, the widespread presence of a given modified nucleoside in RNA of the organisms of the three domains of life is generally taken as evidence that the family of corresponding homologous (orthologous/ paralogous) modification enzymes has a very ancient common evolutionary origin, before the separation of the three domains (Cermakian and Cedergren, 1998). This
- tRNA modification rRNA modification

tRNA modification

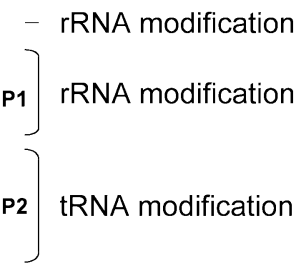

Fig. 10. Probable scenario for the functional evolution of the archaeal genes coding for S-AdoMet-dependent RNA(uracil,

C5)-methyltransferases. The black triangles with HGT indicate when a bacterial

RumA-type enzyme was acquired by HGT.

The encircled symbol ' $S$ ' is used for the gene speciation of the Thermococcales and $N$. equitans lineages; the encircled symbol ' $D$ ' for a duplication event; the encircled symbol 'Sp' for the diversification of the

Thermococcales lineage. The symbol ' $F$ ' indicates the functional shift from the $\mathrm{m}^{5} \mathrm{U}-54$ formation in tRNAs to $\mathrm{m}^{5} \mathrm{U}$ formation in rRNAs (black circle) or from the $\mathrm{m}^{5} \mathrm{U}$ formation in rRNA to $\mathrm{m}^{5} \mathrm{U}-54$ formation in tRNAs (black rectangle). assumption must be taken with caution. Indeed, we show that the S-AdoMet-dependent $\mathrm{m}^{5} \mathrm{U}$ formation in RNA probably appeared first in the bacterial domain and was transferred by HGT only later to the other domains. Based on this functional information, it is not possible to predict the type of specificity of the primordial enzyme for tRNA, rRNA or both. An interesting hypothesis is that the primordial enzyme could have displayed a 'relaxed/dual' specificity. Only during evolution of a few bacterial groups (i.e. Proteobacteria), distinct activities for site-specific RNA(uracil, C5)-methyltransferases could have appeared after duplication or HGT events, followed by subfunctionalization of genes. This would give rise to the present bacterial trmA- and rumB-type gene subfamilies in addition to the existing rumA-type genes, each coding for a site-specific enzyme catalysing the formation of $\mathrm{m}^{5} \mathrm{U}$ at different locations in tRNA and rRNA. Concerning the ancestors of the eukaryotic TRM2 genes and of the archaeal genes (two paralogues in Thermococcales and unique gene in $N$. equitans), our results clearly show that they all were acquired from ancestor rumA-type genes via HGT from unidentified bacterial donors.

\section{Experimental procedures}

\section{Construction of $\mathrm{N}$-terminal $\mathrm{His}_{6}$-tagged PAB0719- and PAB0760-overexpressing plasmids}

The PAB0760 and PAB0719 ORFs were amplified by PCR from $P$. abyssi genomic DNA, using the Vent DNA polymerase (Biolabs) and the following primers (sequence in small characters corresponds to genome sequence): AAAACATatgaggggaatcataaagggag (PAB0760fw) and AAAAGAATtcaccttctcctgagcttaacg (PAB0760rev) or AAAACATatgaggggagtcataagaaagc (PAB0719fw) and AAAAGAATTCagactagcttcgcaacgagctc (PAB0719rev). The 
'forward' (fw) and 'reverse' (rev) primers created an Ndel site at the ATG start codon and an EcoRI site overlapping the TGA stop codon respectively. The resulting PCR products were digested with $\mathrm{Ndel}$ and EcoRI restriction enzymes and cloned into the pET28b vector (Novagen), cleaved with the same enzymes. The resulting vectors were used to transform the E. coli BL21 (DE3) Codon-Plus ${ }^{\mathrm{TM}}$ (Novagen) expression cells.

\section{Purification of the recombinant proteins}

Expression cells were grown at $37^{\circ} \mathrm{C}$ in $1 \mathrm{I}$ of Luria-Bertani medium (Invitrogen) containing $50 \mu \mathrm{g} \mathrm{ml}^{-1}$ kanamycin and $30 \mu \mathrm{g} \mathrm{ml}^{-1}$ chloramphenicol until $\mathrm{OD}_{600}=0.8$. After induction of the PAB0760 or PAB0719 proteins expression by isopropyl $\beta$-D-thiogalactopyranoside (IPTG, Eurobio) at final concentration of $1 \mathrm{mM}$, the cultures were further grown at $20^{\circ} \mathrm{C}$ for $3 \mathrm{~h}$. After harvesting the cells by centrifugation, the pellets were re-suspended in 5 volumes of lysis buffer containing $50 \mathrm{mM}$ sodium phosphate $\mathrm{pH} 8.0,1 \mathrm{M} \mathrm{NaCl}, 5 \mathrm{mM}$ $\beta$-mercaptoethanol, $10 \mathrm{mM}$ imidazole and $1 \%(\mathrm{v} / \mathrm{v})$ protease inhibitor cocktail for the purification of histidine-tagged proteins (Sigma). Cells were broken by ultrasonication and centrifuged for $30 \mathrm{~min}$ at $20000 \mathrm{~g}$ at $4^{\circ} \mathrm{C}$. Supernatants were loaded onto an Ni-NTA superflow resin (Qiagen) and washed with lysis buffer containing $300 \mathrm{mM} \mathrm{NaCl}$ and $20 \mathrm{mM}$ imidazole. PAB0719 or PAB0760 proteins were eluted with lysis buffer containing $300 \mathrm{mM} \mathrm{NaCl}$ and $250 \mathrm{mM}$ imidazole. Fractions containing the PAB0760 or PAB0719 proteins (431 and 425 amino acids in length respectively) were pooled. The absorption spectrum of the purified PAB0719 protein was immediately measured. Proteins were diluted in lysis buffer containing $300 \mathrm{mM} \mathrm{NaCl}$ and $250 \mathrm{mM}$ imidazole and 50\% (v/v) glycerol, aliquoted and stored at $-20^{\circ} \mathrm{C}$.

\section{Preparation of the RNA substrates}

Non-labelled and $\left[\alpha{ }^{32} \mathrm{P}\right]-U T P$ (GE Healthcare) labelled fulllength or D-arm-lacking tRNA ${ }^{\text {Asp }}$ transcripts from $P$. abyssi or yeast were prepared by in vitro transcription with T7 RNA polymerase (Promega) of linearized plasmids harbouring the corresponding synthetic genes while their purification by urea gels electrophoresis were performed as described elsewhere (Grosjean et al., 2007). The rRNA fragment radiolabelled with $\left[\alpha{ }^{32} \mathrm{P}\right]-U T P$ was T7-transcribed in vitro from single-stranded DNA template corresponding to the minus sequence terminated on $3^{\prime}$ by T7 promoter and containing a 2'-O-methyl guanosine in position 2 of $5^{\prime}$ end (Kao et al., 1999).

\section{RNA methylation assays}

To determine the potentiality of the purified recombinant PAB0760 and PAB0719 proteins to catalyse the formation of $\mathrm{m}^{5} \mathrm{U}$ in tRNA, two methods were used. In the first one, transfer of $\left[{ }^{3} \mathrm{H}\right]$-radiolabelled methyl group from $\left[{ }^{3} \mathrm{H}\right] \mathrm{S}$-AdoMet (15 $\mathrm{Ci} \mathrm{mmole}^{-1}$, GE Healthcare) into non-radioactive tRNA was tested. Enzyme kinetics experiments were performed at $50^{\circ} \mathrm{C}$ in $25 \mathrm{mM}$ sodium phosphate buffer $\mathrm{pH} 7.2,25 \mathrm{mM} \mathrm{KCl}$, $5 \mathrm{mM} \mathrm{MgCl} 2,2 \mathrm{mM}$ dithiotreitol, $5 \%$ glycerol, with $2.6 \mu \mathrm{M}$ $\left[{ }^{3} \mathrm{H}\right] \mathrm{S}$-AdoMet, $0.9 \mu \mathrm{M}$ yeast tRNA ${ }^{\text {Asp }}$ transcript and $0.9 \mu \mathrm{M}$ of
PAB0760 or PAB0719 protein in a final volume of $50 \mu \mathrm{l}$. After incubation, the reactions were stopped by addition of cold $5 \%$ $(w / v)$ trichloracetic acid, and the precipitates were collected by vacuum filtration through GF/C filters (Whatman). The filters were washed twice with cold $5 \%(\mathrm{w} / \mathrm{v})$ trichloracetic acid, dried, and the radioactivity was measured by liquid scintillation counting.

In the second method, non-radiolabelled S-AdoMet and $\left[\alpha{ }^{-32} \mathrm{P}\right]-U T P$-labelled RNA transcripts were used to determine the RNA(uracil, C5)-methyltransferases activity of purified recombinant proteins. Three types of substrates were used: transcripts of a full-length $P$. abyssi tRNA ${ }^{\text {Asp }}$ with the T-loop presumably interacting with the D-loop in solution, a Darm-truncated version of the same tRNA ${ }^{\text {Asp }}$, thus unable to generate the classical L-shaped $3 D$ conformation, or a fragment of $23 S$ rRNA (nucleotides 1906-1960) from P. abyssi. To test the enzymatic activity, about $1 \mu \mathrm{g}$ of PAB0760 or PAB0719 proteins (about $20 \mathrm{pmol}$ ) were incubated in $25 \mu \mathrm{l}$ of $25 \mathrm{mM}$ sodium phosphate buffer pH 7.2 containing $25 \mathrm{mM}$ $\mathrm{KCl}, 5 \mathrm{mM} \mathrm{MgCl}_{2}$ (or $0.5 \mathrm{mM}$ EDTA, when the importance of $\mathrm{Mg}^{2+}$ for the enzymatic activity was examined), $2 \mathrm{mM}$ dithiotreitol, $5 \%$ glycerol, $0.1 \mathrm{mg} \mathrm{ml}^{-1}$ bovine serum albumin, $80 \mu \mathrm{M}$ S-AdoMet (Sigma) and about $50 \mathrm{fmol}$ of $\left[{ }^{32} \mathrm{P}\right]-$ radiolabelled RNA at $50^{\circ} \mathrm{C}$ or $80^{\circ} \mathrm{C}$. After incubation, the reactions were stopped by addition of phenol, the RNA was recovered by ethanol precipitation, and the molar content of ribothymidine monophosphate was evaluated after complete digestion of the recovered RNA by nuclease P1 or RNase T2 and subsequent analysis by 2D-TLC as described in detail elsewhere (Grosjean et al., 2007).

\section{Bioinformatic analyses}

We retrieved all the PAB0719 and PAB0760 homologous sequences from 410 completely sequenced archaeal, bacterial and eukaryotic genomes available at the $\mathrm{NCBI}$ (http://www.ncbi.nlm.nih.gov/). Sequences were aligned by CLUSTALW (Thompson et al., 1994) and MUSCLE (Edgar, 2004). The resulting alignments were manually refined using 'ed' from the MUST package (Philippe, 1993). Regions where homology was doubtful were manually removed from further analyses. ML phylogenetic trees were inferred using PHYML (Guindon and Gascuel, 2003) with various models (JTT, WAG and VT) and a $\Gamma$-correction to take into account the heterogeneity of the evolutionary rates between sites (four discrete categories, an estimated alpha parameter and an estimated proportion of invariant sites). The robustness of each node was estimated by bootstrap analyses (1000 replicates of the original data set) using PHYML (Guindon and Gascuel, 2003). Bayesian trees were inferred using MrBayes v.3.0b4 (Ronquist and Huelsenbeck, 2003) with a mixed model of amino acid substitution and a $\Gamma$-correction (four discrete categories and a proportion of invariant sites). MrBayes was run with four chains for one million generations and trees were sampled every 100 generations. To construct the consensus tree, the first 1500 trees were discarded as 'burnin'. To identify known functional domains, we performed searches in the Pfam database (http://www.sanger.ac.uk/Software/Pfam/). Alignments against the Pfam profiles having $E$-values lower than 0.1 were considered significant. 


\section{Acknowledgements}

We thank Richard Giegé from University of Strasbourg, France for a plasmid carrying the yeast tRNA ${ }^{\text {Asp }}$ gene and Clotilde Husson and Dominique Fourmy from CNRS-ICSN (Gif-sur-Yvette, France) for the synthetic P. abyssi rRNA fragment. Kalliopi Trachana, presently working at EMBL/ Heidelberg, Germany was an Erasmus student from the University of Thessaly (Larissa, Greece). We thank Stephen Douthwaite from the University of Southern Denmark (Odense, Denmark) for useful advice and critical reading of the manuscript and Anne-Lise Haenni (University Paris-5, Institut J. Monod, France) for considerable improvements of the text. J.U. acknowledges the financial support from FEBS (long-term postdoctoral fellowship, 2003-06). H.W. is supported by a fellowship from the Association pour la Recherche sur le Cancer. H.G. benefits from a research grant from the CNRS (GEOMEX programme).

\section{References}

Agarwalla, S., Kealey, J.T., Santi, D.V., and Stroud, R.M. (2002) Characterization of the $23 S$ ribosomal RNA m51939 methyltransferase from Escherichia coli. J Biol Chem 277: 8835-8840.

Agarwalla, S., Stroud, R.M., and Gaffney, B.J. (2004) Redox reactions of the iron-sulfur cluster in a ribosomal RNA methyltransferase, RumA: optical and EPR studies. J Biol Chem 279: 34123-34129.

Anantharaman, V., Koonin, E.V., and Aravind, L. (2001) TRAM, a predicted RNA-binding domain, common to tRNA uracil methylation and adenine thiolation enzymes. FEMS Microbiol Lett 197: 215-221.

Anantharaman, V., Koonin, E.V., and Aravind, L. (2002) Comparative genomics and evolution of proteins involved in RNA metabolism. Nucleic Acids Res 30: 1427-1464.

Becker, H.F., Motorin, Y., Sissler, M., Florentz, C., and Grosjean, H. (1997) Major identity determinants for enzymatic formation of ribothymidine and pseudouridine in the $T$ psi-loop of yeast tRNAs. $J$ Mol Biol 274: 505-518.

Becker, H.F., Motorin, Y., Florentz, C., Giege, R., and Grosjean, H. (1998) Pseudouridine and ribothymidine formation in the tRNA-like domain of turnip yellow mosaic virus RNA. Nucleic Acids Res 26: 3991-3997.

Brochier, C., Gribaldo, S., Zivanovic, Y., Confalonieri, F., and Forterre, P. (2005) Nanoarchaea: representatives of a novel archaeal phylum or a fast-evolving euryarchaeal lineage related to Thermococcales? Genome Biol 6: R42.

Bujnicki, J.M., Droogmans, L., Grosjean, H., Purushothaman, S.K., and Lapeyre, B. (2004) Bioinformatics-guided identification and experimental characterization of novel RNA methyltransferases. In Nucleic Acids and Molecular Biology, Vol. 15. Bujnicki, J.M. (ed.). Heidelberg: SpringerVerlag, pp. 139-168.

Cermakian, N., and Cedergren, R. (1998) Modified nucleosides always were: an evolutionary model. In Modification and Editing of RNA. Grosjean, H., and Benne, R. (eds). Washington, DC: American Society for Microbiology Press, pp. 535-541.

Constantinesco, F., Motorin, Y., and Grosjean, H. (1999) Transfer RNA modification enzymes from Pyrococcus furiosus: detection of the enzymatic activities in vitro. Nucleic Acids Res 27: 1308-1315.

Edgar, R.C. (2004) MUSCLE: multiple sequence alignment with high accuracy and high throughput. Nucleic Acids Res 32: 1792-1797.

Edmonds, C.G., Crain, P.F., Gupta, R., Hashizume, T., Hocart, C.H., Kowalak, J.A., et al. (1991) Posttranscriptional modification of tRNA in thermophilic archaea (Archaebacteria). J Bacteriol 173: 3138-3148.

Fauman, E.B., Blumenthal, R.M., and Cheng, X. (1999) Structure and evolution of AdoMet-dependent methyltransferases. In S-Adenosylmethionine-Dependent Methyltransferases: Structures and Functions. Cheng, X., and Blumenthal, R.M. (eds). Singapore: World Scientific, pp. 1-38.

Fleissner, E., and Borek, E. (1962) A new enzyme of RNA synthesis: RNA methylase. Proc Natl Acad Sci USA 48: 1199-1203.

Greenberg, R., and Dudock, B. (1980) Isolation and chracterization of $\mathrm{m}^{5} \mathrm{U}$-methyltransferase from Escherichia coli. J Biol Chem 255: 8296-8302.

Grosjean, H., and Oshima, T. (2007) How nucleic acids cope with high temperature. In Physiology and Biochemistry of Extremophiles. Gerday, C., and Glansdorff, N. (eds). Washington, DC: American Society for Microbiology Press.

Grosjean, H., Edqvist, J., Straby, K.B., and Giege, R. (1996) Enzymatic formation of modified nucleosides in tRNA: dependence on tRNA architecture. J Mol Biol 255: 6785.

Grosjean, H., Droogmans, L., Roovers, M., and Keith, G. (2007) Detection of enzymatic activity of transfer RNA modification enzymes using radiolabeled tRNA substrates. Methods Enzymol 425: 55-101.

Gu, X., Ivanetich, K.M., and Santi, D.V. (1996) Recognition of the T-arm of tRNA by tRNA ( $\left.m^{5} \cup 54\right)$-methyltransferase is not sequence specific. Biochemistry 35: 11652-11659.

Gu, X., Yu, M., Ivanetich, K.M., and Santi, D.V. (1998) Molecular recognition of tRNA by tRNA pseudouridine 55 synthase. Biochemistry 37: 339-343.

Guindon, S., and Gascuel, O. (2003) A simple, fast, and accurate algorithm to estimate large phylogenies by maximum likelihood. Syst Biol 52: 696-704.

Gustafsson, C., Lindstrom, P.H., Hagervall, T.G., Esberg, K.B., and Bjork, G.R. (1991) The trmA promoter has regulatory features and sequence elements in common with the rRNA P1 promoter family of Escherichia coli. J Bacteriol 173: 1757-1764.

Hopper, A.K., Furukawa, A.H., Pham, H.D., and Martin, N.C. (1982) Defects in modification of cytoplasmic and mitochondrial transfer RNAs are caused by single nuclear mutations. Cell 28: 543-550.

Huber, H., Hohn, M.J., Rachel, R., Fuchs, T., Wimmer, V.C., and Stetter, K.O. (2002) A new phylum of Archaea represented by a nanosized hyperthermophilic symbiont. Nature 417: 63-67.

Hur, S., Stroud, R.M., and Finer-Moore, J. (2006) Substrate recognition by RNA 5-methyluridine methyltransferases and pseudouridine synthases: a structural perspective. J Biol Chem 281: 38969-38973.

Kao, C., Zheng, M., and Rudisser, S. (1999) A simple and 
efficient method to reduce nontemplated nucleotide addition at the 3 terminus of RNAs transcribed by T7 RNA polymerase. RNA 5: 1268-1272.

Kowalak, J.A., Dalluge, J.J., McCloskey, J.A., and Stetter, K.O. (1994) The role of posttranscriptional modification in stabilization of transfer RNA from hyperthermophiles. Biochemistry 33: 7869-7876.

Lee, T.T., Agarwalla, S., and Stroud, R.M. (2004) Crystal structure of RumA, an iron-sulfur cluster containing $E$. coli ribosomal RNA 5-methyluridine methyltransferase. Structure 12: 397-407.

Lee, T.T., Agarwalla, S., and Stroud, R.M. (2005) A unique RNA Fold in the RumA-RNA-cofactor ternary complex contributes to substrate selectivity and enzymatic function. Cell 120: 599-611.

Limbach, P.A., Crain, P.F., and McCloskey, J.A. (1994) Summary: the modified nucleosides of RNA. Nucleic Acids Res 22: 2183-2196.

McCloskey, J.A., and Crain, P.F. (1998) The RNA modification database - 1998. Nucleic Acids Res 26: 196-197.

Madsen, C.T., Mengel-Jorgensen, J., Kirpekar, F., and Douthwaite, S. (2003) Identifying the methyltransferases for m(5)U747 and m(5)U1939 in 23S rRNA using MALDI mass spectrometry. Nucleic Acids Res 31: 4738-4746.

Makarova, K.S., and Koonin, E.V. (2005) Evolutionary and functional genomics of the Archaea. Curr Opin Microbiol 8: $586-594$.

Martin, J.L., and McMillan, F.M. (2002) SAM (dependent) I AM: the S-adenosylmethionine-dependent methyltransferase fold. Curr Opin Struct Biol 12: 783-793.

Nordlund, M.E., Johansson, J.O., von Pawel-Rammingen, U., and Bystrom, A.S. (2000) Identification of the TRM2 gene encoding the tRNA $\left(m^{5} \cup 54\right)$ methyltransferase of Saccharomyces cerevisiae. RNA 6: 844-860.

Ny, T., and Bjork, G.R. (1980) Cloning and restriction mapping of the trmA gene coding for transfer ribonucleic acid (5-methyluridine)-methyltransferase in Escherichia coli K-12. J Bacteriol 142: 371-379.

Philippe, H. (1993) MUST, a computer package of Management Utilities for Sequences and Trees. Nucleic Acids Res 21: 5264-5272.

Ronquist, F., and Huelsenbeck, J.P. (2003) MrBayes 3: Bayesian phylogenetic inference under mixed models. Bioinformatics 19: 1572-1574.

Schubert, H.L., Blumenthal, R.M., and Cheng, X. (2003) Many paths to methyltransfer: a chronicle of convergence. Trends Biochem Sci 28: 329-335.

Sprinzl, M., and Vassilenko, K.S. (2005) Compilation of tRNA sequences and sequences of tRNA genes. Nucleic Acids Res 33: D139-D140.

Svensson, I., Boman, H.G., Eriksson, K.G., and Kjellin, K. (1963) Studies on microbial Rna. I. Transfer of methyl groups from methionine to soluble Rna from Escherichia coli. J Mol Biol 7: 254-271.

Tatusov, R.L., Natale, D.A., Garkavtsev, I.V., Tatusova, T.A., Shankavaram, U.T., Rao, B.S., et al. (2001) The COG database: new developments in phylogenetic classification of proteins from complete genomes. Nucleic Acids Res 29: 22-28.

Tatusov, R.L., Fedorova, N.D., Jackson, J.D., Jacobs, A.R., Kiryutin, B., Koonin, E.V., et al. (2003) The COG database: an updated version includes eukaryotes. BMC Bioinformatics 4: 41.

Thompson, J.D., Higgins, D.G., and Gibson, T.J. (1994) CLUSTAL W: improving the sensitivity of progressive multiple sequence alignment through sequence weighting, positionspecific gap penalties and weight matrix choice. Nucleic Acids Res 22: 4673-4680.

Urbonavicius, J., Skouloubris, S., Myllykallio, H., and Grosjean, H. (2005) Identification of a novel gene encoding a flavin-dependent tRNA:m5U methyltransferase in bacteria:evolutionary implications. Nucleic Acids Res 33: 39553964.

Urbonavicius, J., Brochier-Armanet, C., Skouloubris, S., Myllykallio, H., and Grosjean, H. (2007) In vitro detection of the enzymatic activity of folate-dependent tRNA (Uracil-54,C5)-methyltransferase: evolutionary implications. Methods Enzymol 425: 103-119.

Waters, E., Hohn, M.J., Ahel, I., Graham, D.E., Adams, M.D., Barnstead, M., et al. (2003) The genome of Nanoarchaeum equitans: insights into early archaeal evolution and derived parasitism. Proc Natl Acad Sci USA 100: 12984-12988.

\section{Supplementary material}

This material is available as part of the online article from: http://www.blackwell-synergy.com/doi/abs/10.1111/

j.1365-2958.2007.06047.x

(This link will take you to the article abstract).

Please note: Blackwell Publishing is not responsible for the content or functionality of any supplementary materials supplied by the authors. Any queries (other than missing material) should be directed to the corresponding author for the article. 